\title{
Proposta de relatórios para gestão de custos em uma indústria calçadista de pequeno porte da cidade de São \\ Paulo
}

\begin{abstract}
Ivam Ricardo Peleias
Doutorado em Ciências Contábeis pela Faculdade de Economia, Administração e Contabilidade da Universidade de São Paulo - FEA-USP Av. Prof. Luciano Gualberto, 908. São Paulo/SP. CEP: 05508-010

E-mail: ivamrp@fecap.br

Terezinha Balestrin Cestare Bacharelado em Ciências Contábeis pela Faculdade de Economia, Administração e Contabilidade da Universidade de São Paulo - FEA-USP e em Direito pela Faculdade de Direito da Universidade de São Paulo - USP Av. Prof. Luciano Gualberto, 908. São Paulo/SP. CEP: 05508-010 E-mail:bcestare@terra.com.br

Evandir Megliorini Doutorado em Ciências Contábeis pela Faculdade de Economia, Administração e Contabilidade da Universidade de São Paulo - FEA-USP Av. Prof. Luciano Gualberto, 908. São Paulo/SP. CEP: 05508-010 E-mail: e.megliorini@itelefonica.com.br

César de Alencar Leme de Almeida Mestrado em Ciências Contábeis e Atuariais pela FEA-PUC-SP Campos Monte Alegre. Prédio Novo. São Paulo/SP E-mail: calmeida@directapkf.com.br
\end{abstract}

\section{RESUMO}

As micro e pequenas empresas (MPE's) surgem pela ação de empreendedores que buscam realização profissional e pessoal, o que lhes confere um forte componente pessoal em sua administração. Muitas vezes esses indivíduos não possuem conhecimentos teóricos e práticos de gestão, dentre os quais os de custos, úteis ao processo decisório eficaz. Este estudo objetivou a criação de um conjunto de relatórios para a gestão de custos, a ser usado para otimizar os resultados de uma pequena empresa calçadista na cidade de São Paulo. A revisão da literatura revelou entraves no uso do custeio por absorção para fins gerenciais. Apontou o custeio variável como 0 mais apropriado para as pequenas empresas, por permitir a distinção entre custos fixos e variáveis, o melhor entendimento da natureza e do comportamento desses custos em função dos volumes de produção e vendas, e a apuração da margem de contribuição. O trabalho se caracterizou como uma pesquisa-ação, com a realização de análise documental e observação presencial na pequena empresa objeto da pesquisa, o que 
Proposta de relatórios para gestão de custos em uma indústria calçadista de pequeno porte da cidade de São Paulo Ivam Ricardo Peleias, Terezinha Balestrin Cestare, Evandir Megliorini, César de Alencar Leme de Almeida

permitiu obter os elementos que subsidiaram a elaboração do conjunto de relatórios propostos.

Palavras-chave: Microempresa. Gestão de Custos. Custeio Variável.

\section{Reports proposal for cost management in a small shoes factory in São Paulo city}

\section{ABSTRACT}

The micro and small businesses emerge from enterpreneurs who seek personal and professional satisfaction. Because of that, such enterprises are regarded with a strong personal component in their management. In many situations, these people are unaware of practical and theoretical management knowledge, including costs, which are useful for an effective decision making process. The aim of this research was to create a set of reports for the cost management, and such reports are to optimize the outcome of a small shoe business in Sao Paulo city. In relation to the cost methods, the literature revision revealed obstacles concerning the use of the absorption cost for management purposes. The variable cost was appointed as the most appropriate for small businesses as it allows the distinction between variable and fixed costs, between the best understanding of the nature and the behavior of the costs concerning the amount of production and sales as well as the contribution margin examination. This work can be regarded as an action-research, and it allowed the obtaining of the elements that subsidized the designing of the proposed reports.

Key Words: Micro and small businesses. Cost management. Variable cost.

\section{INTRODUÇÃO}

As micros e pequenas empresas desempenham um papel importante no sistema sócio-econômico do país como geradoras de emprego e renda. Coutinho (2006) destaca que em 2005 elas eram cerca de 15,3 milhões, sendo 5,1 milhões formais e 10,2 milhões informais. Davam ocupação a 30 milhões de pessoas entre empregadores e empregados, aproximadamente $71 \%$ do total de ocupados no Brasil. Respondiam também por quase $27 \%$ do total das receitas das empresas em território nacional. $O$ SEBRAE-SP informou, em sua página na Internet em 28 de abril de 2008 (www.sebraesp.com.br), que no Brasil existiam 5,1 milhões de empresas, sendo que desse total, $98 \%$ eram micro e pequenas. Salientou que estas empresas eram responsáveis por $67 \%$ das ocupações e por $20 \%$ do PIB. 
Proposta de relatórios para gestão de custos em uma indústria calçadista de pequeno porte da cidade de São Paulo Ivam Ricardo Peleias, Terezinha Balestrin Cestare, Evandir Megliorini, César de Alencar Leme de Almeida

Apesar da importância das micro e pequenas empresas para o desenvolvimento do país, elas têm dificuldade de se firmarem. O número dessas sociedades constituídas anualmente no Brasil é muito grande; no entanto, muitas delas desaparecem antes de completar cinco anos. Pesquisa do SEBRAE-SP (2005, p. 15) apontou que $29 \%$ delas não chegam a concluir o primeiro ano de atividade, $42 \%$ não atingem o final do segundo ano, 53\% encerram suas atividades antes de completar o terceiro ano, $56 \%$ não ultrapassam o quarto ano e, que este percentual $(56 \%)$ se repete no quinto ano de atividade, conforme Figura 1.

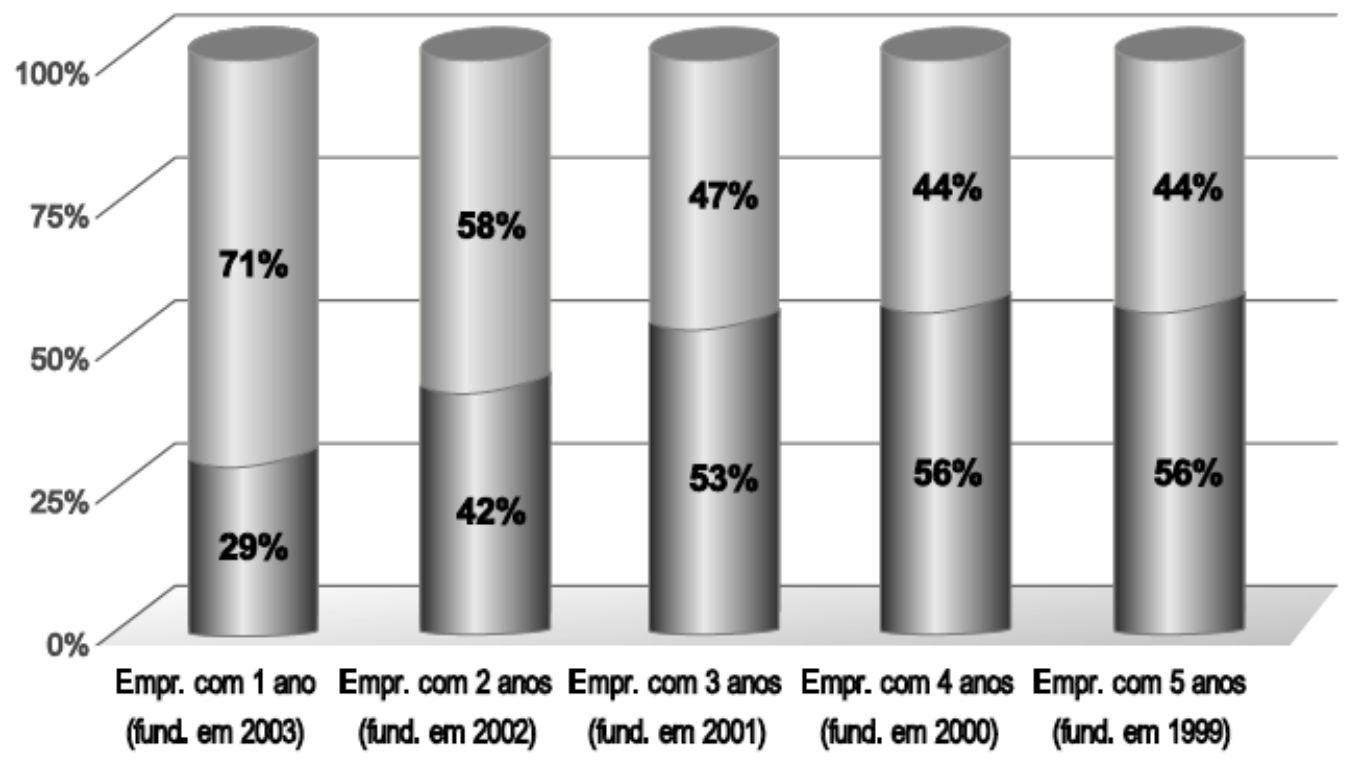

empresas encerradas

empresas em alvidade

Figura 1: Sobrevivência e mortalidade acumulada das empresas, Estado de São Paulo Fonte: SEBRAE-SP (2005, p. 15).

O SEBRAE (2005, p. 34) hierarquizou no mesmo trabalho os principais motivos que levaram ao fechamento dos negócios (Figura 2). Em primeiro lugar, aparece a falta de capital; em segundo lugar, tem-se a falta de clientes/inadimplência; em terceiro lugar destacam-se os problemas de planejamento e administração juntamente com problemas particulares. 
Proposta de relatórios para gestão de custos em uma indústria calçadista de pequeno porte da cidade de São Paulo Ivam Ricardo Peleias, Terezinha Balestrin Cestare, Evandir Megliorini, César de Alencar Leme de Almeida

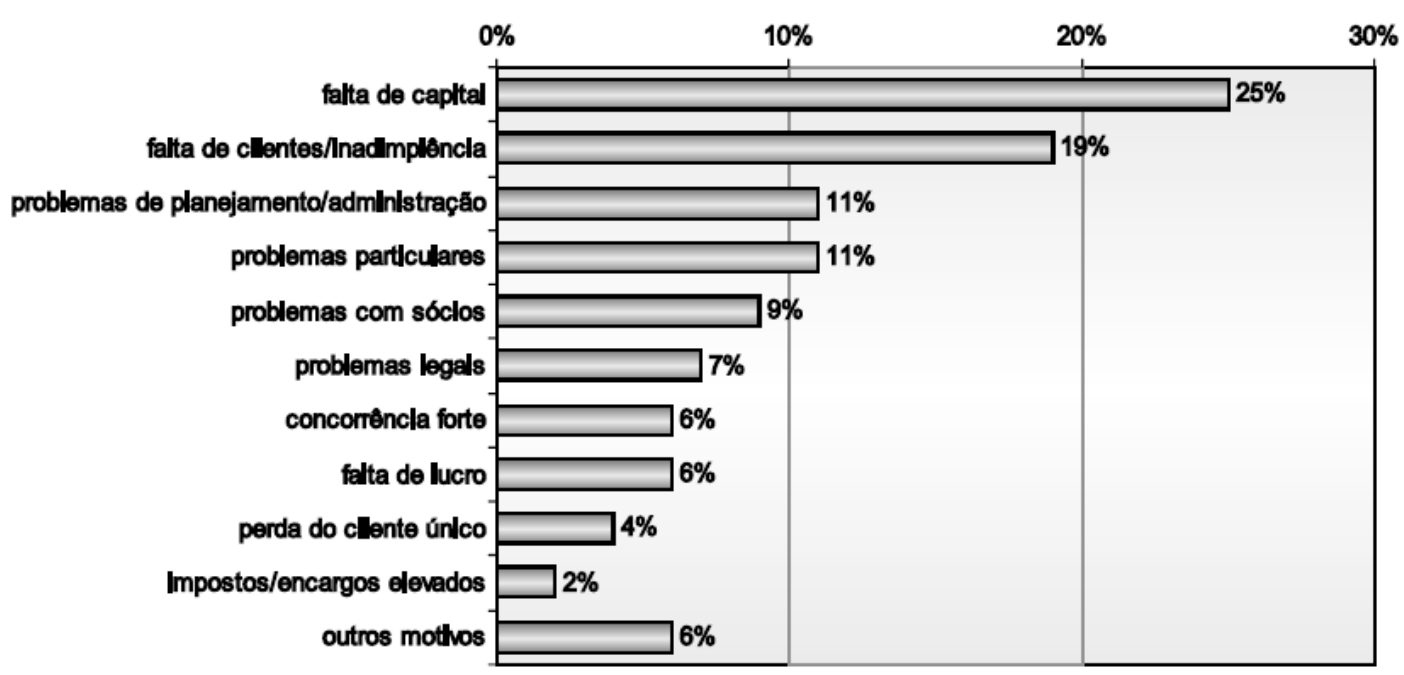

Figura 2- Motivos alegados pelas empresas encerradas para o fechamento do negócio Fonte: SEBRAE-SP (2005, p. 34).

$\mathrm{Na}$ análise dos motivos, o estudo apontou que alguns deles constituem faces distintas de um mesmo problema, por exemplo, a falta de capital pode estar associada ou mesmo ser conseqüência de uma gestão deficiente. Um problema apontado referiuse à gestão de custos destas empresas. Neste quesito, o SEBRAE-SP (2005, p. 37) considerou ser imprescindível que as empresas tenham o controle detalhado dos custos dos produtos e serviços para a adequada precificação, salientando que se deve buscar apoio profissional quando surgirem problemas sérios e de difícil solução.

Ao buscar identificar, de forma exploratória, como as micro e pequenas empresas (MPEs) se organizavam em termos de gestão de custos, grau de controle e domínio que as mesmas mantinham sobre os custos, e como formavam os preços finais que praticavam, o SEBRAE-SP (2002, p. 1-12) empreendeu uma pesquisa junto a 450 MPEs, sendo 150 delas da indústria de transformação, 150 do comércio e 150 de serviços. Constatou-se que, do universo pesquisado, $86 \%$ dos empresários não tinham noção clara da estrutura de custos do principal produto ou serviço que ofereciam ao mercado. Cerca de $33 \%$ desconhecia o valor dos estoques de matérias-primas e mercadorias, 38\% desconhecia o valor de cada hora trabalhada em termos de salários e encargos, e $10 \%$ desconhecia o valor médio mensal de outros custos, tais como aluguel, telefone, energia elétrica, combustíveis, água e gás.

Essas constatações tornam o quadro mais crítico, quando se considera a 
Proposta de relatórios para gestão de custos em uma indústria calçadista de pequeno porte da cidade de São Paulo Ivam Ricardo Peleias, Terezinha Balestrin Cestare, Evandir Megliorini, César de Alencar Leme de Almeida

importância relativa destes itens na estrutura de custos das empresas. É o que se constata ao analisar outra pesquisa (SEBRAE, 1998), realizada junto a 1.142 micro e pequenas empresas do Estado de São Paulo. Este estudo detectou a representatividade de determinados itens de custos, reproduzida na Tabela 1.

\begin{tabular}{|c|c|c|c|}
\hline Itens de custo & Comércio & Indústria & Serviços \\
\hline Gastos com materiais (1) & $75 \%$ & $53 \%$ & $19 \%$ \\
\hline Gastos com empregados & $11 \%$ & $24 \%$ & $56 \%$ \\
\hline Impostos & $8 \%$ & $16 \%$ & $10 \%$ \\
\hline Outros custos (2) & $6 \%$ & $7 \%$ & $15 \%$ \\
\hline Totais & $100 \%$ & $100 \%$ & $100 \%$ \\
\hline
\end{tabular}

Quadro 1 - estrutura relativa de custos de MPE's paulistas - por setor Fonte: SEBRAE (1998).

(1) inclui aquisição de matérias-primas, mercadorias, peças e componentes e serviços de terceiros,

(2) inclui gastos com aluguel, água energia elétrica, telefones, combustíveis e gás, dentre outros

A Tabela aponta que os gastos com matérias-primas e empregados respondiam, nos setores pesquisados, por percentuais que variavam entre $75 \%$ e $86 \%$ dos custos incorridos pelas MPE's pesquisadas.

A falta de um sistema eficaz para a gestão de custos transcende os aspectos contábeis das empresas, tornando-se um problema gerencial. $O$ atual ambiente competitivo torna imprescindível o conhecimento dos custos nos processos decisórios das organizações. Sem conhecer e compreender seus custos, uma empresa não poderá promover mercadorias e serviços, e poderá apostar em projetos que não geram lucros. Pode se não conhecer quais os produtos que contribuem para o lucro e quais não contribuem e, na melhor das hipóteses, o administrador terá apenas uma idéia nebulosa para onde o dinheiro está indo e de qual é a situação da empresa (RESNIK, 1990).

Para realçar essa situação, Martins (2003, p. 218) assinala que a falta do conhecimento do custo dos produtos e serviços gera dificuldades para a formação do preço de venda, quando as empresas determinam o preço com base em seus custos, situação denominada pelo autor como de preços de dentro para fora.

Em função do aumento da competitividade na maioria dos setores, industriais, 
Proposta de relatórios para gestão de custos em uma indústria calçadista de pequeno porte da cidade de São Paulo Ivam Ricardo Peleias, Terezinha Balestrin Cestare, Evandir Megliorini, César de Alencar Leme de

comerciais ou de serviços, Martins (2003, p. 22) salienta que "[...] as empresas já não podem mais definir seus preços de acordo com os custos incorridos, e sim com base nos preços praticados no mercado em que atuam." O autor (2003, p. 22) reforça que "o conhecimento dos custos é vital para saber se, dado o preço, o produto é rentável, ou, se não rentável, se é possível reduzi-los (os custos)."

Outra contribuição importante acerca do conhecimento dos custos refere-se à forma como eles se comportam em diferentes níveis de atividades. A separação entre custos fixos e variáveis permite encontrar o nível mínimo de atividades que a empresa deve operar, para cobrir os custos totais, e para mensurar o retorno do investimento aos proprietários. Além disso, permite aos gestores determinar níveis mínimos de preços, políticas de descontos, e a tomada de decisões entre continuar realizando atividades ou tercerizá-las, dentre outras.

Longenecker et al. (1997, p. 334) salientam que "as pequenas empresas freqüentemente desconsideram diferenças entre custos fixos e variáveis e os tratam de forma idêntica para a determinação de preços. "Para os autores, essa abordagem chamada de determinação do preço médio acaba se revelando perigosa quando o volume de produção e vendas oscila em diferentes patamares. Caso a empresa tenha uma mesma estrutura de custos fixos, sua distribuição por quantidade maior ou menor resulta em menor ou maior custo médio. Nestas condições, a determinação do preço tem dupla influência na receita total de vendas, diretamente como parte da equação da receita e, indiretamente, por meio de seu impacto sobre a quantidade demandada.

Esta situação foi observada em uma pequena empresa estabelecida desde 1972 na cidade de São Paulo, fabricante de calçados femininos. A pesquisa permitiu verificar que a empresa não possui controles formais de custos, situação que dificulta a gestão dos custos da empresa e a tomada de decisões relativas a preços de venda. Como contribuição, foi preparada e apresentada à empresa uma proposta de relatórios para a gestão de custos apoiada no método de custeio variável. 
Proposta de relatórios para gestão de custos em uma indústria calçadista de pequeno porte da cidade de São Paulo Ivam Ricardo Peleias, Terezinha Balestrin Cestare, Evandir Megliorini, César de Alencar Leme de

\section{REVISÃO DA LITERATURA}

\subsection{Contexto do Desenvolvimento das Micro e Pequenas Empresas no Brasil}

De acordo com Pinheiro (1996), o fim da Segunda Guerra Mundial foi o marco inicial para grandes mudanças no mundo. A necessidade de recuperar a Europa fez com que as relações entre as nações, em especial as mais desenvolvidas, se intensificassem sob vários aspectos. Surgiram grandes conglomerados empresariais, acumuladores de recursos tecnológicos e de capitais, que passaram a exercer grande influência no processo econômico global.

Emerge nesse contexto uma relação importante entre os grandes conglomerados e as pequenas e médias unidades produtivas, pela complementaridade que estas exercem no processo econômico, ao permitirem a execução e distribuição de bens e serviços com maior vantagem. Tal situação se deveu, dentre outros fatores, à existência de muitas empresas de pequeno porte que, por sua versatilidade e desconcentração espacial das atividades que realizavam, serviram como elemento de desenvolvimento em áreas periféricas não alcançadas pelos grandes conglomerados. Permitiram ainda uma maior e melhor distribuição de renda, como uma forma de atenuar desequilíbrios regionais.

Referido movimento social e econômico causou a necessidade de se criarem regras de proteção para essas unidades menores de produção, em relação aos grandes conglomerados. Tal necessidade se tornou mais visível diante da crise econômica enfrentada por muitos países, no final dos anos 1970, que gerou um nível crescente de desemprego e endividamento público, evidenciando a necessidade de se questionar o modelo de desenvolvimento vigente. A crise levou à necessidade de fortalecer as organizações de menor porte, que revelaram possuir grande capacidade de adaptação a mudanças, além de serem uma alternativa para a absorção de apreciável quantidade de mão-de-obra ociosa (KASSAI, 1996).

Esse fenômeno também se fez presente no Brasil. Todavia, a atuação da pequena empresa ocorria quase que totalmente na informalidade, pois só assim conseguia sobreviver. Foi entre o final dos anos 1970 e início dos anos 1980 que o 
Proposta de relatórios para gestão de custos em uma indústria calçadista de pequeno porte da cidade de São Paulo Ivam Ricardo Peleias, Terezinha Balestrin Cestare, Evandir Megliorini, César de Alencar Leme de

governo, mais preocupado com as questões fiscais, começou a tratar do atendimento às necessidades das MPE's. Nessa época foram promulgados o Decreto-Lei №. $1780 / 80$, concedendo isenção do imposto sobre a renda às empresas de pequeno porte, e a Lei oㅜ 7.256/84, na forma de Estatuto da microempresa.

A preocupação com as MPE's é destacada na Constituição Federal de 1988 em seu artigo 179. A Carta Magna do país fornece as principais diretrizes para o tratamento legislativo dessas organizações. Ao ler o referido artigo, depreende-se a intenção de acompanhar tendências mundialmente adotadas para proteger as MPE's. Algumas razões decorrem de sua importância no cenário nacional e capacidade de absorção de mão-de-obra, fatores relevantes para o desenvolvimento econômico e social, geração e distribuição de renda. Entretanto, é possível dizer que a pretendida proteção ainda não se fez plenamente, situação que se observa pela quantidade de pequenos empreendimentos que atuam na informalidade.

A preocupação governamental levou à edição de outros normativos, dentre eles o Projeto da Lei Geral das Micro e Pequenas Empresas, embrião da Lei Complementar no 123 , de 14 de dezembro de 2006. O texto teve por base proposta apresentada pelo SEBRAE, incorporando o substitutivo que englobou diversos projetos que tramitavam na Câmara dos Deputados sobre o assunto. O projeto aprovado trouxe regras que procuravam garantir um melhor ambiente para a competitividade do segmento no país.

Um ponto importante da Lei Complementar, abordado em seu art. 3o, foi a definição, em nível nacional, do que vem a ser MPE, unificando os vários critérios adotados. Consideram-se microempresas, a sociedade empresária, a sociedade simples e o empresário, cuja receita bruta anual seja igual ou inferior a $R \$ 240.000,00$, e empresas de pequeno porte aquelas em que a receita bruta seja igual ou inferior a $R \$$ $2.400 .000,00$.

Outra questão importante foi a criação do Regime Especial Unificado de Arrecadação de Tributos e Contribuições devidos pelas Microempresas e Empresas de Pequeno Porte, o Simples Nacional, conforme o art. 12 da Lei Complementar 123/2006. Este sistema, em vigor a partir de $1^{\circ}$ de julho de 2007 , implica o recolhimento mensal de uma porcentagem da receita bruta, mediante documento único de arrecadação. Este 
Proposta de relatórios para gestão de custos em uma indústria calçadista de pequeno porte da cidade de São Paulo Ivam Ricardo Peleias, Terezinha Balestrin Cestare, Evandir Megliorini, César de Alencar Leme de

recolhimento substituiu o pagamento dos impostos e contribuições já abrangidos pelo Simples, além do ICMS e do ISS. Relativamente ao Simples Nacional, Fabretti (2006, p. 213) adverte que não se trata de "imposto único", mas da unificação do pagamento de diversos impostos e contribuições em um único documento de arrecadação federal denominado DARF-SIMPLES.

Relativamente aos controles e registros contábeis, as MPE's poderão adotar contabilidade simplificada para os registros e controles das operações realizadas, conforme disposto no art. 27 da referida Lei Complementar. As orientações sobre a implementação e uso deste processo contábil simplificado constam no Manual de Procedimentos Contábeis para Micro e Pequenas Empresas, trabalho conjunto do CFC e SEBRAE (2002). A importância e a utilidade da Contabilidade para as MPE's pode ser aquilatada pela promulgação da Resolução CFC No. 1115/2007, que aprovou Norma Brasileira de Contabilidade aplicável a essas organizações, considerando também as determinações contidas no Novo Código Civil Brasileiro e as recomendações da Lei Complementar 123/2006 (CFC, 2007).

\subsection{A Contabilidade e a Pequena Empresa}

A Contabilidade é o meio mais eficiente para fornecer informações precisas e ajudar os empresários na gestão e controle de seus negócios. Ao realçar a importância da Contabilidade, os presidentes do CFC e do SEBRAE declararam, em mensagem conjunta na $5^{\text {a }}$ edição (2002) do Manual de Procedimentos Contábeis para Micro e Pequenas Empresas, que

a Contabilidade constitui-se instrumento de gestão imprescindível, principalmente no Brasil, onde o pequeno empreendedor, enfrentando um cenário econômico de oscilações freqüentes, de altas taxas de juros e uma carga tributária próxima dos $35 \%$ do $\mathrm{PIB}$, precisa se valer de todas as alternativas possíveis para se manter de portas abertas e seguir gerando emprego e renda.

Neste Manual (2002, p. 23-24), os representantes do CFC e o SEBRAE 
Proposta de relatórios para gestão de custos em uma indústria calçadista de pequeno porte da cidade de São Paulo Ivam Ricardo Peleias, Terezinha Balestrin Cestare, Evandir Megliorini, César de Alencar Leme de Almeida

destacaram que "uma empresa sem Contabilidade é uma entidade sem memória, sem identidade e sem as mínimas condições de sobreviver ou de planejar seu crescimento. " Para estes órgãos, a contabilidade é útil sob vários aspectos:

Legal: proporciona os fundamentos necessários para enfrentar situações como perícias judiciais, falências e concordatas, dissidências societárias e fiscalização da Previdência Social;

Gerencial: propicia aos empresários as informações para a tomada de decisões. A decisão sobre investir, reduzir custos, modificar uma linha de produtos, ou praticar outros atos gerenciais deve se basear em dados técnicos extraídos dos registros contábeis, sob pena de se pôr o patrimônio da empresa em risco;

Social: a falta da escrituração contábil é uma das principais dificuldades para se avaliar a economia informal, distorcendo as estatísticas no Brasil. O desconhecimento da realidade econômica nacional gera decisões dissociadas das necessidades das empresas e da sociedade em geral.

Relativamente ao aspecto gerencial, o potencial informacional da Contabilidade não é totalmente explorado pelas micro e pequenas empresas, e muitas vezes é relegado a um plano secundário. Nesta perspectiva, Madeira (2003, p. 29) aponta que

[...] o pequeno empreendedor não tem visão e conhecimento sobre a importância da Contabilidade, e declara que esta é um "mal necessário", e que o contador serve apenas para fazer sua declaração de imposto de renda e atender às exigências fiscais.

Tardiamente, esse pequeno empreendedor acaba se conscientizando do potencial da Contabilidade, quando sua empresa já se encontra em processo de descontinuidade, fracassada e morrendo (MADEIRA, 2003, p. 29). Isso pode ser verificado em pesquisa realizada por Ferreira Neto (2002), que estudou o uso de informações contábeis no processo decisório em pequenas empresas. $O$ autor resgatou os principais problemas vivenciados por essas sociedades, em trabalho publicado no ano de 1982, no Caderno de Temática Contábil do Boletim IOB. A leitura do trabalho de Ferreira Neto (2002, p. 81) revela que decorridos mais de vinte e cinco anos, algumas 
Proposta de relatórios para gestão de custos em uma indústria calçadista de pequeno porte da cidade de São Paulo Ivam Ricardo Peleias, Terezinha Balestrin Cestare, Evandir Megliorini, César de Alencar Leme de Almeida

situações vividas pelas pequenas e médias empresas permaneciam atuais, entre elas:

1) normalmente a Contabilidade é realizada para atender às exigências fiscais e não como um instrumento para assessorar o pequeno empresário em suas decisões;

2) nem sempre a Contabilidade reflete a realidade econômico-financeira dessas empresas;

3) normalmente, o pequeno empresário conhece bem o processo industrial (produção) de sua empresa, confessando-se pouco entendido em administração financeira. Dificilmente possui assessores para auxiliá-lo na administração, e tem muita dificuldade em interpretar os balancetes e outros relatórios contábeis, apresentados pelos escritórios de Contabilidade;

4) normalmente não há política de estoques; desconhece-se a verdadeira situação financeira da empresa; não se sabe qual é o seu capital de giro próprio; o seu grau de endividamento, os principais fatores que contribuem para a queda da rentabilidade, o seu nível de imobilização, a composição de suas dívidas (curto ou longo prazo), as fontes de financiamento menos onerosas, as melhores alternativas de investimentos etc.

\subsection{Gestão de Custos na Pequena Empresa}

Os pequenos negócios não são versões menores de grandes negócios (WELSH; WHITE, 1981, p. 18), Apesar da contundência da afirmação, pode-se depreender que o propósito de um sistema de custos em uma pequena empresa não é diferente daquele de sociedades de maior porte. Em ambas, um sistema de custos deve ser capaz de responder às necessidades informativas dos gestores. Devido às características das pequenas empresas, com estruturas organizacionais menos burocráticas, comparativamente às grandes organizações, sua contabilidade de custos deveria ter um grau de complexidade menor.

Nesse sentido, as especificidades das pequenas empresas devem ser consideradas quando da estruturação de seu sistema de gestão de custos. Para Leone (1999, p. 92-93), as especificidades destas empresas podem ser apresentadas em três vias: organizacionais, decisórias e individuais. Dentro de cada uma destas especificidades, destacam-se: 
Proposta de relatórios para gestão de custos em uma indústria calçadista de pequeno porte da cidade de São Paulo Ivam Ricardo Peleias, Terezinha Balestrin Cestare, Evandir Megliorini, César de Alencar Leme de Almeida

Organizacionais: empresas mais centralizadas, com estrutura organizacional simples, necessitando menor quantidade de unidades ou funções administrativas; menor controle sobre seu ambiente externo; a estratégia é intuitiva e pouco formalizada; personalização da gestão na pessoa do seu proprietário-dirigente;

Decisórias: tomada de decisão baseada na experiência, no julgamento ou na intuição do proprietário-dirigente e, na maior parte do tempo, dentro de uma ótica operacional de curto prazo; o poder de direção é localizado e centralizado; os dados necessários à análise da tomada de decisão nem sempre estão disponíveis;

Individuais: papel predominante de um só indivíduo na organização, o qual influencia todos os aspectos da empresa; o perfil do dirigente é mais o de um estrategista que corre riscos do que o de um administrador-gestor que procura aplicar uma estratégia minimizando os riscos.

Consideradas estas especificidades, a gestão da pequena empresa acaba se diferenciando daquelas de maior porte. Estas sociedades dispõem de escassos recursos humanos e financeiros que, associados à centralização que os dirigentes exercem, resultam em um ambiente que apresenta dificuldades de implementar práticas de gestão mais sofisticadas.

Nesse sentido, Callado e Callado (1998, p. 469) mencionam que um sistema de contabilidade de custos adotado por uma empresa precisa ser compatível com sua estrutura organizacional, seus procedimentos operacionais e seu tipo de informação sobre custos que a administração desejar.

\section{METODOLOGIA DA PESQUISA}

Os procedimentos metodológicos adotados seguiram a tipologia proposta por Vergara (2000). Quanto aos fins, a pesquisa é exploratória e aplicada, pois buscou resolver problemas concretos mais imediatos, e teve finalidade prática. Quanto aos meios, é uma pequisa-ação, com análise documental (MARTINS, 2006) e pesquisa de campo (VERGARA, 2000).

A pesquisa-ação justifica-se na medida em que identifica problemas relevantes 
Proposta de relatórios para gestão de custos em uma indústria calçadista de pequeno porte da cidade de São Paulo Ivam Ricardo Peleias, Terezinha Balestrin Cestare, Evandir Megliorini, César de Alencar Leme de Almeida

dentro da situação investigada, define um programa de ação para a resolução e acompanha os resultados obtidos (THIOLLENT, 1999, p. 100). Para Vergara (2000, p.49), a pesquisa-ação "é um tipo particular de pesquisa participante que supõe intervenção participativa na realidade social. Quanto aos fins é, portanto, intervencionista".

O objetivo da pesquisa-ação, conforme Telles (2001, p. 86), "é a disponibilização de alternativas ou propostas de encaminhamentos e / ou soluções a problemas específicos, dentro de um grupo, uma organização ou um programa. " Para Thiollent (1994, p.15), "na pesquisa-ação os pesquisadores desempenham um papel ativo no equacionamento dos problemas encontrados, no acompanhamento e na avaliação das ações desencadeadas em função dos problemas. "Nas palavras de Martins (2006, p. 47), a pesquisa-ação se justifica nas organizações como "uma proposta de pesquisa mais aberta com características de diagnóstico e consultoria para clarear uma situação complexa e encaminhar possíveis ações, especialmente em situações insatisfatórias ou de crise."

\section{APRESENTAÇÃO E DISCUSSÃO DOS RESULTADOS}

\subsection{Identificação e Caracterização da Empresa}

A empresa objeto do estudo é fabricante de sapatos femininos, produzindo artesanalmente, sob pedidos de seus clientes. Foi fundada em 1972, na cidade de São Paulo, por iniciativa de um empreendedor que permaneceu à frente dos negócios até 1981, quando então os filhos assumiram o comando da empresa.

Atualmente, as atividades administrativas e financeiras são desenvolvidas por um desses sucessores-proprietários, que atua também como modelista. A outra sucessora-proprietária realiza atividades relacionadas ao atendimento aos clientes, incumbindo-se da anotação dos pedidos. Somam-se aos proprietários oito funcionários que atuam nas atividades de produção, administração e vendas.

Contrariamente às estatísticas de sobrevida de empresas de mesmo porte, essa fábrica de calçados se mantém ativa, mesmo não praticando um processo de gestão 
Proposta de relatórios para gestão de custos em uma indústria calçadista de pequeno porte da cidade de São Paulo Ivam Ricardo Peleias, Terezinha Balestrin Cestare, Evandir Megliorini, César de Alencar Leme de

academicamente considerado adequado. Os atuais gestores creditam essa longevidade à qualidade dos produtos, que permitiu constituir uma carteira de clientes fiéis, porém, exigentes.

Atingiu em 2006 um faturamento de cerca de $R \$ 400.000,00$, o que a enquadra como microempresa pelo Estatuto da Microempresa. Como sua receita bruta anual naquele ano superou $\mathrm{R} \$ 240.000,00$, enquadrou-se no regime tributário do SIMPLES, do qual é optante como empresa de pequeno porte.

Produziu em 2006, em média, oitenta pares de calçados mensais. O processo de produção é totalmente manual, envolvendo inúmeras operações, organizadas em cinco etapas: corte do couro ou tecido; pesponto (costura); colocação de palmilha, apontamento e montagem; preparação, colocação de sola e salto; pranchamento, limpeza, retoque, acabamento e fixação do salto.

O tempo de realização de cada uma dessas etapas varia de acordo com a complexidade de cada modelo de calçado e do material empregado. As principais matérias-primas usadas na fabricação são o couro ou tecido, sola, saltos, cola e pregos pequenos (tachas).

\subsection{Proposta de Controle dos Custos com o Uso do Custeio Direto ou Variável}

À época de realização do estudo, a empresa não possuía quaisquer controles de custos, e suas decisões relativas à precificação dos produtos e descontos eram tomadas de forma intuitiva. Para que fosse possível oferecer uma contribuição aos gestores, a proposição nesta etapa do trabalho foi elaborar, para posterior implantação, um conjunto de relatórios, denominado de "modelo de gestão de custos". Não foi objetivo nesta etapa elaborar relatórios ou formulações matemáticas para precificação dos produtos.

Dentre os métodos de custeio, considerou-se como premissa que o custeio variável é mais adequado do que o custeio por absorção para a empresa objeto do estudo, ou mesmo o custeio ABC. O custeio por absorção, usado para relatórios externos pelas empresas em geral, pode levar a problemas gerenciais (GARRISON; NOREEN, 2001, p. 205), incluindo decisões inadequadas de determinação de preço e 
Proposta de relatórios para gestão de custos em uma indústria calçadista de pequeno porte da cidade de São Paulo Ivam Ricardo Peleias, Terezinha Balestrin Cestare, Evandir Megliorini, César de Alencar Leme de Almeida

decisões de deixar de fabricar produtos que na verdade são lucrativos.

O problema referido pelos autores está relacionado ao tratamento dado aos custos fixos. Por esse método, os custos fixos são apropriados à produção, de modo que os custos unitários dos produtos parecem variáveis ao se alterarem em diferentes volumes de produção.

$O$ custeio $A B C$ pode oferecer informações de custos para decisões estratégicas. Entretanto, exige em sua implantação um quadro contábil tecnicamente treinado, apoiado por uma equipe mista com pessoas de várias áreas da empresa (GARRISON; NOREEN, 2001, p. 225).

O emprego do custeio variável permite identificar os produtos que mais contribuem para a cobertura dos custos fixos e são mais ou menos lucrativos para a empresa, revelando uma dimensão da importância do produto. Estas informações auxiliam a traçar uma política comercial mais adequada, elegendo os produtos de maior rentabilidade e menor custo de produção (SILVA; OLIVEIRA FILHO, 2000).

Definido o método de custeio, o passo seguinte foi identificar a natureza dos gastos da empresa, segregando-os em fixos e variáveis, conforme apresentado no Quadro 2, e propor um conjunto de relatórios para custeio. Para facilitar a apresentação, os termos despesas e custos serão tratados apenas como custos.

\begin{tabular}{|c|c|}
\hline \multicolumn{2}{|c|}{ Custos Fixos e Variáveis } \\
\hline Fixos & Variáveis \\
\hline Mão-obra-Indireta & Mão-de-obra Direta \\
\hline Pró-Labore & Materiais Diretos \\
\hline Aluguel & Embalagem \\
\hline Energia Elétrica & Comissões sobre Vendas \\
\hline Depreciação & \\
\hline Água & \\
\hline Telefone & \\
\hline Seguros & \\
\hline Honorários Contábeis & \\
\hline Despesas Bancárias & \\
\hline Despesas com Correio & \\
\hline Despesas com Combustível & \\
\hline Outros Custos Fixos & \\
\hline
\end{tabular}

Quadro 2 - Identificação dos custos fixos e variáveis 
Proposta de relatórios para gestão de custos em uma indústria calçadista de pequeno porte da cidade de São Paulo Ivam Ricardo Peleias, Terezinha Balestrin Cestare, Evandir Megliorini, César de Alencar Leme de Almeida

A separação dos custos em fixos e variáveis subsidiou a elaboração do conjunto de relatórios a seguir apresentado e analisado.

Relatório dos Custos Variáveis por Par de Sapato:

Este relatório, Figura 3, discrimina os elementos de custos classificáveis como variáveis, identificados com cada produto.

\begin{tabular}{|c|c|c|c|c|c|}
\hline \multicolumn{6}{|c|}{ Relatório dos Custos Variáveis por Par de Sapato } \\
\hline & & Io de Sapat & & & \\
\hline \multirow[b]{2}{*}{ 1. Materiais diretos } & \multicolumn{2}{|c|}{ Consumo } & \multicolumn{2}{|c|}{ Custos - $R \$$} & \multirow{2}{*}{$\begin{array}{c}\text { Custo do } \\
\text { Produto - } \\
R \$\end{array}$} \\
\hline & Qtde. & $\begin{array}{l}\text { Unidade de } \\
\text { Medida }\end{array}$ & Unitários & $\begin{array}{l}\text { Unidade de } \\
\text { Medida }\end{array}$ & \\
\hline \multicolumn{6}{|l|}{ Couro } \\
\hline \multicolumn{6}{|l|}{ Tecido } \\
\hline \multicolumn{6}{|l|}{ Forro } \\
\hline \multicolumn{6}{|l|}{ Cadarço } \\
\hline \multicolumn{6}{|l|}{ Linha } \\
\hline \multicolumn{6}{|l|}{ Cola Benzina } \\
\hline \multirow{2}{*}{\multicolumn{6}{|c|}{$\begin{array}{c}\text { Palmilha } \\
\text { Contraforte }\end{array}$}} \\
\hline & & & & & \\
\hline \multicolumn{6}{|l|}{ Tachas } \\
\hline \multicolumn{6}{|l|}{ Cola forte } \\
\hline \multicolumn{6}{|l|}{ Salto } \\
\hline \multicolumn{6}{|l|}{ Embalagem } \\
\hline \multicolumn{6}{|l|}{ Outros } \\
\hline \multicolumn{6}{|l|}{ 2. Mão-de-obra direta } \\
\hline \multirow{2}{*}{\multicolumn{6}{|c|}{ Corte }} \\
\hline & & & & & \\
\hline \multicolumn{6}{|l|}{ Pesponto (costura) } \\
\hline \multicolumn{6}{|l|}{ Apontamento (montagem) } \\
\hline \multicolumn{6}{|l|}{ Preparação } \\
\hline \multicolumn{6}{|l|}{ Pranchamento (acabamento) } \\
\hline \multicolumn{5}{|c|}{ 3. Despesas de Vendas: } & \\
\hline & Com & ões & & & \\
\hline Total de & os Varié & is por Par de & japato & & \\
\hline
\end{tabular}

Figura 3 - Custos e Despesas Variáveis

Relatório dos Custos Variáveis do Mês:

Neste relatório, apresentado na Figura 4, são relacionados os diferentes modelos de sapatos fabricados no mês, a quantidade de cada um deles, e os custos variáveis correspondentes. 
Proposta de relatórios para gestão de custos em uma indústria calçadista de pequeno porte da cidade de São Paulo Ivam Ricardo Peleias, Terezinha Balestrin Cestare, Evandir Megliorini, César de Alencar Leme de

Almeida

\begin{tabular}{|l|c|c|c|}
\hline \multicolumn{5}{|c|}{ Relatório dos Custos Variáveis do Mês } \\
\hline \multirow{2}{*}{ Modelos de Sapato } & $\begin{array}{c}\text { Qtde. } \\
\text { Fabricada }\end{array}$ & Custos Variáveis - R\$) \\
\cline { 3 - 4 } & & Unitário & Total \\
\hline & & & \\
\hline & & & \\
\hline & & & \\
\hline & & & \\
\hline & & & \\
\hline & & & \\
\hline \multicolumn{2}{|c|}{ TOTAL DOS CUSTOS VARIÁVEIS } & \\
\hline
\end{tabular}

Figura 4 - Custos Variáveis do Mês

Relatório dos Custos Fixos do Mês:

O terceiro relatório, apresentado na Figura 5, discrimina os custos fixos do mês. Nesta fase do trabalho foi proposto um relatório sem a segregação destes custos por unidade organizacional, o que deverá ser objeto de estudo em uma segunda etapa do trabalho.

\begin{tabular}{|c|c|}
\hline \multicolumn{2}{|c|}{ Relatório dos Custos Fixos do Mês } \\
\hline Item de custo & Custo - R\$ \\
\hline Mão-de-obra indireta & \\
\hline Pró-labore & \\
\hline Aluguel & \\
\hline Energia elétrica & \\
\hline Água & \\
\hline Depreciação & \\
\hline Telefone & \\
\hline Seguros & \\
\hline Honorários contábeis & \\
\hline Despesas bancárias & \\
\hline Despesas com correios & \\
\hline Despesas com combustível & \\
\hline Outras & \\
\hline TOTAL DOS CUSTOS FIXOS & \\
\hline
\end{tabular}

Figura 5 - Custos Fixos do Mês

Relatório de Resultados:

No quarto relatório, apresentado na Figura 6, calcula-se o resultado mensal da 
Proposta de relatórios para gestão de custos em uma indústria calçadista de pequeno porte da cidade de São Paulo Ivam Ricardo Peleias, Terezinha Balestrin Cestare, Evandir Megliorini, César de Alencar Leme de

empresa, destacando-se a margem de contribuição de cada modelo de sapato.

\begin{tabular}{|l|l|l|l|l|l|l|l|}
\hline $\begin{array}{l}\text { Modelo } \\
\text { de } \\
\text { Sapato }\end{array}$ & $\begin{array}{c}\text { Qtde. } \\
\text { vendida }\end{array}$ & \multicolumn{2}{|c|}{ Custo variável } & \multicolumn{2}{c|}{ Preço de venda } & \multicolumn{2}{c|}{ Margem de Contribuição } \\
\hline & & & & & & & Total \\
\hline & & & & & & & \\
\hline & & & & & & & \\
\hline & & & & & & & \\
\hline & & & & & & & \\
\hline & & & & & & & \\
\hline & & & & & & \\
\hline & & & & & & \\
\hline & & & & & & & \\
\hline
\end{tabular}

Figura 6 - Resultado do Mês

\subsection{Controles Gerenciais}

A implementação do conjunto de relatórios propostos é considerada viável em função de diversos fatores, dentre os quais se destaca que foram elaborados a partir do conhecimento da realidade da empresa, e que durante a elaboração dos mesmos foi possível discutir com os gestores envolvidos conhecimentos básicos sobre custos, com ênfase no custeio variável;

À medida que a implementação destes relatórios se consolidar, outros informes são visualizados como importantes, entre eles, um relatório de custos por área da empresa. Espera-se que isso venha a ser um passo importante para a implantação do orçamento empresarial.

\section{CONSIDERAÇÕES FINAIS}

A revisão da literatura evidenciou a dificuldade de sobrevida das micro e pequenas empresas e apontou, entre as diferentes causas, o fato de as mesmas não possuírem um sistema eficaz para gerenciar seus custos, o que não permite conhecer a 
Proposta de relatórios para gestão de custos em uma indústria calçadista de pequeno porte da cidade de São Paulo Ivam Ricardo Peleias, Terezinha Balestrin Cestare, Evandir Megliorini, César de Alencar Leme de Almeida

lucratividade de seus produtos. Esta situação se aplica à empresa estudada.

As limitações organizacionais e estruturais dessas empresas não devem constituir-se em empecilhos para a implementação de um sistema de gestão de custos, mesmo que simplificado, como foi a proposta apresentada, porém, deve revestir-se de confiabilidade, coerência e atualização.

Como proposta para a gestão de custos foi apresentado um conjunto de relatórios denominado de "modelo de gestão de custos", fundamentado no método de custeio variável, pelo qual podem ser identificados os produtos com margem de contribuição positiva, mediante a qual é possível cobrir os custos fixos e proporcionar lucro para a empresa.

Desse modo, permite-se à empresa, ao contar com um sistema de gestão de custos, informações suficientes para apurar os custos estimados de novos pedidos, proporcionando melhor gestão do preço de venda, oferecer descontos para pedidos especiais, dentre outras situações que requerem a tomada de decisões baseadas em informações de custos.

Ainda que a entidade pesquisada não se enquadre no quadro constatado nos trabalhos localizados e analisados, acerca da sobrevida das pequenas e médias empresas, o estudo de sua realidade evidenciou que a ausência de uma gestão profissional, com informações de custos, tem tornado sua luta pela sobrevivência mais difícil.

O uso da pesquisa-ação teve como grande objetivo fornecer aos sujeitos envolvidos os motivos, as vantagens e a necessidade da adoção de meios planejados para a gestão de custos. Para finalizar, espera-se que a organização pesquisada não padeça dos males apontados nos trabalhos analisados durante a revisão da literatura, que atingem grande parte das MPE's no Brasil.

\section{REFERÊNCIAS}

BRASIL. Decreto-Lei. n. 1780 de 14 de abril de 1980. Concede isenção do imposto sobre a renda às empresas de pequeno porte e dispensa obrigações acessórias. 
Proposta de relatórios para gestão de custos em uma indústria calçadista de pequeno porte da cidade de São Paulo

Ivam Ricardo Peleias, Terezinha Balestrin Cestare, Evandir Megliorini, César de Alencar Leme de

Almeida

Disponível em: http://www6.senado.gov.br/sicon/ExecutaPesquisaLegislacao.action. Acesso em 19/jan/2007.

. Lei n. 7256 de 27 de novembro de 1984. Estabelece normas integrantes do estatuto da microempresa, relativa ao tratamento diferenciado, simplificado e favorecido nos campos administrativo, tributário, previdenciário, trabalhista, creditício e de desenvolvimento empresarial. Disponível em: http://www6.senado.gov.br/sicon/ExecutaPesquisaLegislacao.action. Acesso em: 19/jan/2007.

. Constituição Federal de 1988, de 05 de outubro de 1988. Disponível em: http://www6.senado.gov.br/sicon/ExecutaPesquisaLegislacao.action. Acesso em: 19/jan/2007.

. Lei Complementar no 123 de 14 de dezembro de 2006. Institui o Estatuto Nacional da Microempresa e da Empresa de Pequeno Porte. Disponível em: http://www.planalto.gov.br/ccivil_03/Leis/LCP/Quadro_Lcp.htm. Acesso em: 19/dez/2006.

CALlado, A. A. C., CALLADO, A. L. C. (1998). Custos na tomada de decisões em empresas rurais. Anais do V Congresso da Associação Brasileira de Custos. Fortaleza. Disponível em: www.abc.org.br. Acesso em 02/out/2006.

CONSELHO FEDERAL DE CONTABILIDADE / SEBRAE. (2002). Manual de procedimentos contábeis para micro e pequenas empresas / Daniel Salgueiro da Silva. [et al.]; coordenação de Pedro Coelho Neto. (5 ed.). Brasília: CFC/SEBRAE. Disponível em: http://www.cfc.org.br/uparq/ManuMicro.pdf. Acesso em: 19/de jan/2007.

. (2007). Resolução CFC No. 1115, de 14 de dezembro de 2007. Aprova a NBC T 19.13. Escrituração contábil simplificada para microempresa e empresa de pequeno porte. Brasília. Disponível em: http://www.cfc.org.br/sisweb/sre/detalhes_sre.aspx?Codigo=2007/001115. Acesso em: 17/jul/2008.

COUTINHO, L. (2006). Baixo endividamento das micro e pequenas empresas revela o restrito acesso ao crédito. São Paulo: Serasa Notícias. Disponível em: www.serasa.com.br. Acesso em: 30/abril/2008.

FABRETTI, L. C. (2006). Direito tributário aplicado. São Paulo: Atlas.

FERREIRA NETO, B. J. (2002). Informações contábeis e o processo decisório em pequenas empresas. 140 f. (Dissertação de Mestrado). Faculdade de Economia, Administração e Contabilidade da Universidade de São Paulo - FEA/USP. 
Proposta de relatórios para gestão de custos em uma indústria calçadista de pequeno porte da cidade de São Paulo Ivam Ricardo Peleias, Terezinha Balestrin Cestare, Evandir Megliorini, César de Alencar Leme de Almeida

GARRISON, R. H.; NOREEN, E. W. Contabilidade gerencial. Rio de Janeiro: LTC Livros Técnicos e Científicos Editora S. A., 2001.

KASSAI, S. As empresas de pequeno porte e a contabilidade. (1996). $259 \mathrm{f}$. (Dissertação de Mestrado). Faculdade de Economia, Administração e Contabilidade da Universidade de São Paulo - FEA/USP.

LEONE, N. M. de C. P. G. (1999). As especificidades das pequenas e médias empresas. São Paulo: Revista de Administração, v. 34, n. 2, p. 91-94, abril/junho.

LONGENECKER, J. G.; MOORE, C. W.; PETTY, J. W. (1997). Administração de pequenas empresas. São Paulo: Makron Books.

MADEIRA, D. K. (2003). Sistema de informação contábil para gestão das micro e pequenas empresas enquadradas no SIMPLES. (Dissertação de Mestrado). Universidade Federal de Santa Catarina - UFSC.

MARTINS, E. (2003). Contabilidade de custos. (9 ed.). São Paulo: Atlas.

MARTINS, G.A. (2006). Estudo de Caso: uma estratégia de pesquisa. São Paulo: Atlas.

PINHEIRO, M. (1996). Gestão e desempenho das empresas de pequeno porte. $269 \mathrm{f}$. (Tese de Doutorado). Faculdade de Economia, Administração e Contabilidade da Universidade de São Paulo - FEA/USP.

RESNIK, P. (1990). A bíblia da pequena empresa. São Paulo: McGraw-Hill, Makron Books.

SEBRAE-SP. A presença das micro e pequenas empresas na economia brasileira. Página da Internet. Disponível em: www.sebraesp.com.br. Acesso em: 28/abril/2008.

SEBRAE-SP. (1998). Estudo comparativo: pequenas empresas (MPEs) versus grandes empresas (MGEs) no estado de São Paulo. Relatório de Pesquisa. Disponível em: www.sebraesp.com.br. Acesso em 12/mai/2008.

SEBRAE-SP. (2002). A gestão dos custos nas MPEs paulistas: um estudo exploratório. Relatório de Pesquisa. Disponível em: www.sebraesp.com.br. Acesso em 12/mai/2008.

SEBRAE-SP. (2005). Sobrevivência e mortalidade das empresas paulistas de 1 a 5 anos. Disponível em: www.sebraesp.com.br. Acesso em 12/mai/2008.

SILVA, A. H. da; OLIVEIRA FILHO, P. N. (2000). Praticando custos e preços na MPE. Recife. SEBRAE. Disponível em: www.sebrae.com.br. Acesso em: 12/mai/2008. 
Proposta de relatórios para gestão de custos em uma indústria calçadista de pequeno porte da cidade de São Paulo Ivam Ricardo Peleias, Terezinha Balestrin Cestare, Evandir Megliorini, César de Alencar Leme de Almeida

TELLES, R. (2001). Considerações sobre tipificação da investigação científica e pesquisa qualitativa. Revista Álvares Penteado. São Paulo. V. 3 n. 6, jun.

THIOLLENT, M. (1994). Metodologia da Pesquisa-ação. São Paulo: Cortez. (1999). Notas para o debate sobre pesquisa-ação. Repensando a Pesquisa Participante. Carlos Rodrigues Brandão (org.) São Paulo: Ed. Brasiliense.

VERGARA, S. C. (2000). Projetos e relatórios de pesquisa em administração. (3 ed.). São Paulo: Atlas.

WELSH, J. A.; WHITE, J. F. (1981). A Small Business Is Not a Little Big Business. Harvard Business Review. Boston: Jul/Aug. Vol. 59, Iss. 4; pg. 18, 10 pgs.

Data de Submissão: 26/04/2010

Data de Aceite: 02/07/2010 